\title{
Beyond Absolutism: Guiding Principles Needed for Humanitarian Medicine: Reply
}

\author{
David Robert Welling
}

Published online: 10 June 2010

(C) Société Internationale de Chirurgie 2010

Dr. Leeds skillfully points out some of the foibles of humanitarian medicine and is correct in stating that there are usually no moral absolutes in those kinds of activities [1]. We chose to use a metaphor in our article which he finds to be faulty because of "...the complex relativism inherent to most humanitarian work." Our "seven sins" was a way to organize the subject and to clarify our thinking about it. Perhaps we could have titled the article "The Seven Blunders...," if "sins" seems a little harsh or negative. A primary objective of the article was to stimulate discussion about the several challenges of humanitarian medicine. It would appear that healthy dialogue has taken place because the article was published, and for this we are grateful. Perhaps, in the future, principles could be crafted, as Dr. Leeds suggests, in order to “...provide realistic guidance to managing the complexity and moral ambiguity of such work." It would be gratifying and most useful if the humanitarian medicine community could come together and agree on certain fundamental goals and objectives of the work, which would be written down as a charter. These statements could be expressed in a positive way, avoiding the negativism of "sins."

The challenge in such an activity would not be in the gathering together of proper ideas for such a charter. Many of us are more than willing to provide credible ideas. The challenge would be to find the organization in the world with the clout and credibility to put together such an effort. Who in the world should tackle this challenge?

\section{Reference}

Leeds IL (2010) Beyond absolutism: guiding principles needed for humanitarian medicine: letter to the editor. World J Surg. doi: 10.1007/s00268-010-0612-3
D. R. Welling $(\square)$

Departments of Surgery and Anatomy, Uniformed Services

University of the Health Sciences, Bethesda, USA

e-mail: dwelling@usuhs.mil 